\title{
Mechanical Harvester for Fresh Market Quality Stemless Sweet Cherries
}

\author{
D. L. Peterson, S. D. Wolford
}

\begin{abstract}
A mechanical harvester was developed to harvest sweet cherries for the fresh market. The harvester operator used joysticks to position and engage a rapid displacement actuator on main scaffolds to effect fruit removal. The three main scaffolds per tree were inclined to reduce damage as cherries fell to the catching surface. Ethrel was used to reduce the fruit retention force of mature cherries to enable removal without stems and damage. A catching conveyor was designed to intercept falling fruit without damage and elevate the fruit to a collecting conveyor. Mechanically harvested cherries had only 2-6\% more damage than did commercially hand-harvested cherries and graded 85-92\% marketable.
\end{abstract}

Keywords. Mechanical harvester, Sweet cherry, Quality, Stemless.

T The supply of a skilled, harvest workforce is a concern of the sweet cherry (Prunus avium L.) industry in the United States (Warner, 1997; Hansen, 1999a). Between $40 \%$ and $60 \%$ of orchard workers are undocumented, and the U.S. Immigration and Naturalization Service has increased efforts to eliminate them (Hansen, 1999b). Holt (1999) suggested that increased mechanization could be an effective tool to increase worker productivity and keep U.S. fruit industries competitive in the world market. No fresh market sweet cherries are mechanically harvested (Sarig et al., 1999) despite substantial research (Gaston et al., 1959; Norton et al., 1962; Markwardt et al., 1964; Halderson, 1966). The main problems preventing machine harvest of sweet cherries are: 1) difficulty in fruit removal, 2) removal with stems, and 3 ) bruising and other fruit damage caused during detachment, fall through the tree canopy, and from catching surfaces. Traditionally, the industry has dictated that sweet cherries sold on the fresh market must have stems. Innovative growers in the state of Washington (Hansen, 1999c) have developed a system of training and cultural practices designed to be compatible with mechanical harvesting that yields stemless sweet cherries for the fresh market. Ethrel (2-chloroethyl phosphonic acid) was used to reduce the fruit retention force of mature cherries to enable removal without stems while minimizing detachment damage. In test

Article was submitted for review in September 2000; approved for publication by the Power \& Machinery Division of ASAE in January 2001.

All programs and services of the USDA are offered on a nondiscriminatory basis with regard to race, color, national origin, religion, sex, age, marital status, or handicap. Mention of a trade name or product does not constitute a guarantee, warranty, or endorsement of the product.

The authors are Donald L. Peterson, ASAE Fellow Engineer, Agricultural Engineer, and Scott D. Wolford, Mechanical Engineering Technician, USDA-ARS, Appalachian Fruit Research Station, Kearneysville, West Virginia. Corresponding author: Donald L. Peterson, USDA-ARS, Appalachian Fruit Research Station, 45 Wiltshire Road, Kearneysville, WV 25430; phone: 304-725-3451, ext. 324; fax: 304-728-2340; e-mail: dpeterso@afrs.ars.usda.gov. marketing at retail outlets, consumer acceptance of these stemless sweet cherries has been very high. However, attempts to use traditional mechanical harvesters with inertia shakers with this new concept have resulted in excessive damage to the cherries for the fresh market.

\section{OBJECTIVES}

The objective of this research was to develop a mechanical harvesting system for stemless, fresh market quality sweet cherries. To accomplish this objective, the following tasks needed to be accomplished: (1) determine compatible tree training and cultural practices, (2) develop an effective fruit removal actuator and positioning system, (3) develop fruit catching/collecting components that minimize damage, and (4) test the system under field conditions to determine feasibility.

\section{Harvester Design}

The harvester was three-wheeled (front wheel steerable), all-wheel-hydraulic-drive with a driver positioned at the left rear (facing forward) who controlled all operations (figs. 1 and 2). A $18.6 \mathrm{~kW}$ gasoline engine that drove a $57 \mathrm{~L} / \mathrm{min}$. pressure-compensated, variable-volume hydraulic pump supplied power. The catching conveyor and positioning mechanisms for the rapid-displacement-actuator (RDA) a hydraulic cylinder that rapidly displaces scaffold-limbs for fruit removal (Peterson et al., 1999) - were structurally tied together on a track system and could be positioned $1 \mathrm{~m}$ along the tree row.

The driver used a hydraulic foot-valve for ground speed control (forward and reverse) to position the harvester along the tree row, and hydraulic joysticks to position the RDA to a scaffold limb (fig. 3). The RDA could be positioned in three directions along and into the scaffold for the desired position. The positioning mechanism was designed to efficiently transmit the action of the RDA when scaffolds were $45^{\circ}$ to $65^{\circ}$ to the horizontal. The RDA had a $28.6 \mathrm{~mm}$ bore and 


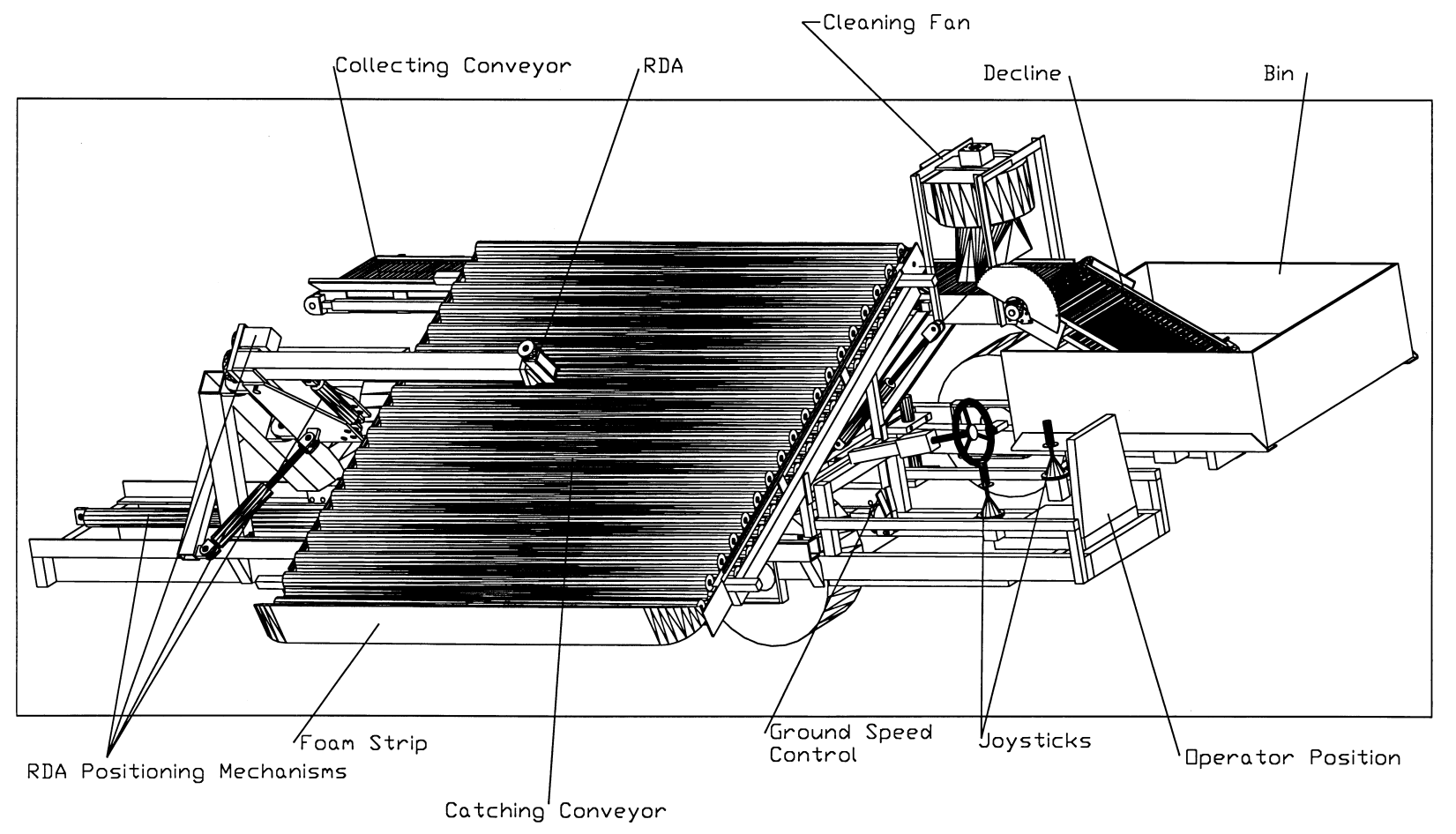

Figure 1. Schematic of mechanical harvester for sweet cherries.

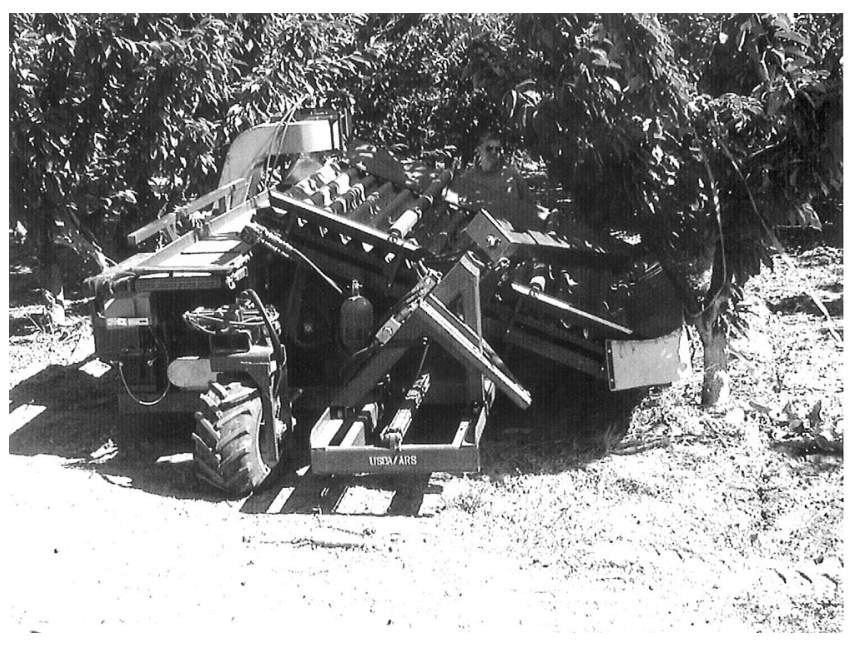

Figure 2. Overview of mechanical harvester for sweet cherries.

$47 \mathrm{~mm}$ stroke. Attached to the rod end of the RDA was a 90$\mathrm{mm}$ diameter aluminum disk that partially enclosed a 75-mm diameter gum rubber disk that engaged the scaffold. The aluminum disk engaged a microswitch mounted on the cylinder to activate the RDA. A spring concentric with the RDA's cylinder rod prevented the aluminum disk from activating the switch until the disk was firmly pressed against the scaffold, compressing the spring. A $3.8 \mathrm{~L}$ accumulator, pressurized to $8300 \mathrm{kPa}$, supplied fluid to the RDA to generate the required limb acceleration and displacement to effect fruit removal. A simple electric circuit controlled activation of the RDA. By adjusting a time delay relay, the RDA could be activated for a single impact or multiple impacts.

The catching conveyor was inclined $24^{\circ}$ to the horizontal and had a $200 \mathrm{~mm} \times 200 \mathrm{~mm}$ strip of $64 \mathrm{~kg} / \mathrm{m}^{3}$ density open-cell polyester foam (Wm. T. Burnett Co., Baltimore, Md.) at the lower edge to allow close positioning to the tree trunk. The top surface of the foam strip was angled $16^{\circ}$ to the horizontal to feed cherries into the conveyor. The energy-absorbing catching conveyor caught the fruit and elevated it to a collecting conveyor (fig 4). The catching conveyor consisted of $28-m m$ i.d. $\times 19-m m$ thick Armaflex pipe insulation (Armstrong World Industries, Lancaster, Penn.) surrounding $19 \mathrm{~mm}$ schedule 40 aluminum pipes. The pipes were 2032 $\mathrm{mm}$ long and were supported by B-1-1 attachments of 2050 roller chain spaced every $127 \mathrm{~mm}$. The pipe insulation was covered with a $0.56-\mathrm{mm}$ thick polyurethane-coated nylon fabric that formed pockets to collect and transport the fruit.

The design was such that the pockets were stretched at the outlet end of the conveyor to carefully discharge the fruit onto a transfer incline. This incline was covered with $12-\mathrm{mm}$ thick Poron (Rogers Corp., East Woodstock, Conn.) and transferred the fruit to a 46-mm wide collecting conveyor. The collecting conveyor used a Series 900 Flush Grid plastic perforated belt (Intralox, Harahan, La.) that transported the fruit to the rear and then declined to lower the fruit into a revolving bin for distribution. Before the conveyor declined, a fan pulled air through the conveyor to remove leaves and other light trash. An ultrasonic sensor was used to minimize fruit drop into the bin and ensure even fill. This sensor sensed the level of fruit in the bin and triggered a circuit to automatically raise the decline before the conveyor touched the fruit.

For a complete harvesting system, a mirror image of the above-described machine would be needed on the opposite side of the tree with a seal between the two halves. Only one half of the machine was constructed for research purposes. 


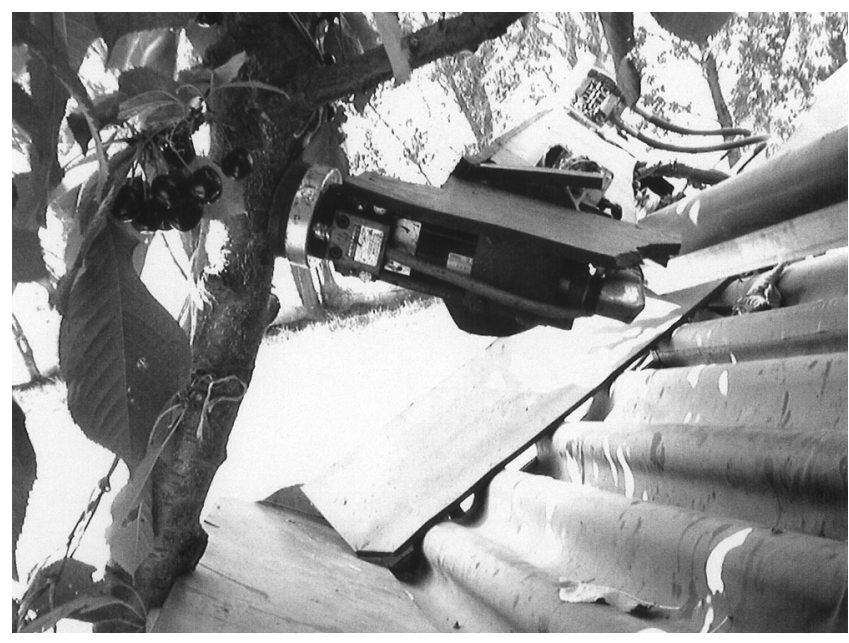

Figure 3. Rapid-displacement-actuator positioned against a scaffold.

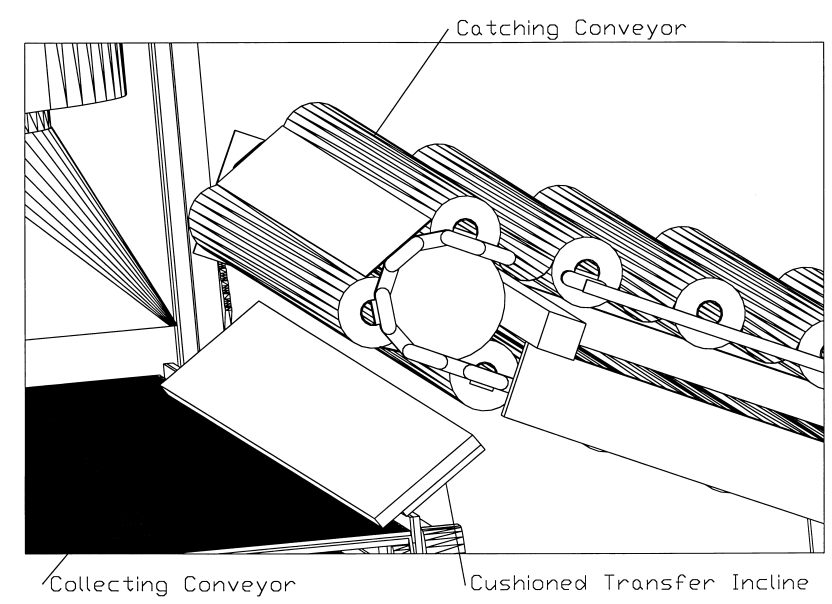

Figure 4. Conveyors schematic.

\section{Test Procedures}

The harvester was tested in two orchards during June and July 2000. The first orchard was located near Roosevelt, Washington. Trees were in their sixth leaf and were spaced $2.14 \mathrm{~m}$ in the row and $4.6 \mathrm{~m}$ between rows. Each tree had three main scaffold branches approximately $120^{\circ}$ apart with one scaffold perpendicular to the tree row (looking from above). The next tree in the row had the scaffold perpendicular to the row on the opposite side of the preceding tree and this pattern alternated the entire row. The training scheme had each scaffold inclined $45^{\circ}$ to $65^{\circ}$ to the horizontal. Since sweet cherry trees are very upright in their growth habit, most scaffolds were in reality much steeper, with some scaffolds up to $85^{\circ}$ to the horizontal. Scaffolds ranged from 70 to $90 \mathrm{~mm}$ in diameter near the trunk of the tree. The orchard was predominately Bing, with Van planted every fifth tree as a pollinator. The second orchard was near Moxee, Washington, and was in its fourth leaf. The cultivar was Lapin, and the training system was the same as previously described. Scaffolds ranged from 40 to $70 \mathrm{~mm}$ in diameter near the trunk of the tree.
Ethrel (2-chloroethyl phosphonic acid) was sprayed on the trees 10-12 days before the anticipated harvest date. Bukovac et al. (1971), working with sweet cherries in Michigan, found that Ethrel applied 7-14 days before harvest could reduce the fruit removal force from 500-600 g to less than $300 \mathrm{~g}$. Ethrel had been used on the Roosevelt orchards in 1998 and 1999, and after 10-12 days the fruit retention force was sufficiently reduced to permit removal by manually bumping the scaffolds. Nearly all of the removed fruit were stemless (Harris, 2000, personal communication).

For all tests, the driver positioned the harvester so the lower edge of the catching conveyor was centered on and in close proximity to the tree trunk. The driver then used the joysticks to position the RDA perpendicular to a scaffold and active the impact. For Bing and Van, each scaffold was impacted two to three times (single impacts with 2-3 seconds in between) at one or two locations. Impact locations were dictated by the placement of lateral branches, but the driver tried to pick a location as high as possible on the scaffold and then lower near the trunk. Considerable pruning was required on some scaffolds to permit visibility for the driver and access by the RDA. Two bins from 60 trees of Bing were machine harvested. On the same day, two bins of commercially hand-harvested Bing were randomly selected for comparison.

Ten trees of Van were machine harvested as described above. An additional ten trees of Van were shaken with a commercial inertia trunk shaker (provided by Don Stackhouse, custom cherry harvester, Hickman, Calif.), and the fruit from half of the tree was caught and collected by the experimental harvester. This test was conducted to determine the effect of detachment damage between the two removal techniques. Lapin were given two treatments of ten trees each. In the first treatment, the scaffolds were impacted two to three times (single impacts). In the second treatment, the scaffolds were impacted with three to four multiple impacts in sequence with $0.2 \mathrm{sec}$ cycle time between impacts. In all tests, percent fruit removal was estimated since sufficient labor was not available to harvest the cherries left on the trees. For each harvest, cherries were randomly sampled to determine the range of fruit detachment force. During harvest, cherries were collected in $1200 \times 1200 \times 400 \mathrm{~mm}$ bins. Maximum depth of cherries in the bins was $230 \mathrm{~mm}$ (approximately $160 \mathrm{~kg}$ ). The bins were stored in refrigeration for three to five days before grading.

To evaluate the catching conveyor for damage potential, nine 100-cherry samples of Lapin were carefully hand picked. Three samples were dropped onto the moving catching conveyor from $1 \mathrm{~m}$, and three samples were dropped from $2 \mathrm{~m}$. The cherries were collected on the collecting conveyor. Three samples were kept as controls. These cherries were kept in refrigeration for four days before evaluation.

All fruit samples were carefully graded by an experienced sweet cherry buyer (Doug Fields, Excel Fruit Brokerage, Yakima, Wash.). Samples from all the Bing bins were collected and graded as marketable (no damage) or culls (natural defects, bruising, or cuts). For Van and Lapin, three random samples of 100 cherries from each treatment were selected and graded as marketable or culls. Lapin from the drop tests were graded with the same procedure. For grading purposes, cherries with stems were not included in the 
samples. SAS statistical software (Version 7, SAS Institute Inc., Cary, N.C.) was used to analyze the data.

\section{Test Results And Discussion}

All machine components operated as expected. After practice, the driver easily controlled the positioning of the RDA. However, he had considerable difficulty seeing the scaffolds and locating a "clear" section of the limb to position the RDA. Pruning of some limbs and leaves before the harvest helped. Conveyors and bin filler were very effective. Little fruit was lost in front of or behind the catching conveyor. Some cherries that hit the lower part of the catching conveyor bounced toward the opposite side of the tree. During detachment, some energy was transmitted to the opposite side of the tree, and cherries were also lost to the ground. A mirror image harvester on the opposite side of the tree with an effective tree seal would be required. There was little visible limb damage from the RDA. Damage occurred only when the rubber disk was pressed against a limb stub or not squarely positioned against the limb.

South Central Washington had a much cooler and wetter spring than normal in 2000. As a result, the Ethrel was not as effective in reducing fruit retention force as in past years (Harris, 2000, personal communication). For Bing, the main scaffolds were very upright, which made it difficult to transmit the energy from the RDA effectively. This factor and the lack of response from Ethrel resulted in estimated fruit removal of about $50 \%$. However, the machine-harvested Bing averaged $87 \%$ marketable with $13 \%$ total culls, compared to $91 \%$ marketable with $9 \%$ total culls for the commercially hand-harvested cherries. Machine-harvested cherries had less than $5 \%$ stems.

Fruit retention force for Van ranged between 300 and $400 \mathrm{~g}$. The main scaffolds were oriented in a flatter plane than the Bing, but not as flat as desired. Fruit removal using the RDA was better with Van than with Bing and was estimated to be $70-80 \%$. Fruit removal with the inertia shaker was better than with the RDA and was estimated to be better than $90 \%$. However, fruit quality with the RDA was significantly better, $86.3 \%$ marketable, than with the inertia shaker, $79 \%$ marketable (table 1). The better quality was a result of less bruising and cuts with the RDA detachment than with the inertia shaker.
Ethrel had a better response on Lapin, with fruit retention forces ranging between 200 and $300 \mathrm{~g}$. The main scaffolds were oriented between $50^{\circ}$ and $70^{\circ}$. The trees were smaller than with Bing or Van, and fruit removal was estimated to be about $85 \%$ with single impacts and better than $90 \%$ with multiple impacts. Fruit quality was good with all treatments (table 1). The hand-harvested and machine-harvested cherries with the single-impact RDA both graded $92.3 \%$ marketable. The machine-harvested cherries with the multiple-impact RDA had slightly more bruising and cuts than either of the other treatments and averaged $85 \%$ marketable. Multiple impacts caused more fruit movement and therefore more damage. Drop tests onto the catching conveyor yielded about $4 \%$ bruising. A cherry dropping $2 \mathrm{~m}$ did not suffer any more damage than a cherry dropping $1 \mathrm{~m}$.

\section{Conclusions}

The experimental harvester demonstrated potential for harvesting stemless sweet cherries with 85-92\% fresh market quality and only 2-6\% more damage than commercial hand harvesting. Effective response of Ethrel is critical to this harvesting concept to ensure fruit removal and to minimize detachment damage. Training of the main scaffolds is also critical to allow positioning of the RDA and efficient energy transfer from the RDA to the scaffold. Positioning of the RDA using hydraulic joysticks was effective and efficient. Using an inertia trunk shaker doubled the damage of harvested cherries compared to using the RDA. The catching/collecting system was effective with low damage inflicted to the cherries. More extensive testing with a complete harvest system (units on each side of the tree row) is needed before commercialization.

\section{ACKNOWLEDGEMENTS}

Special thanks to the Washington State Tree Fruit Research Commission for partially funding the research and to Bob Harris of Moxee, Washington; Denny Hayden of Pasco, Washington; and Rod Riggs of Selah, Washington, for providing advice, orchards, and support in planning and conducting the research.

Table 1. Average grade of sweet cherries.

\begin{tabular}{|c|c|c|c|c|c|c|}
\hline \multirow[b]{2}{*}{ Harvest Date } & \multirow[b]{2}{*}{ Cultivar } & \multirow[b]{2}{*}{ Treatment } & \multicolumn{4}{|c|}{ Packout (\%) } \\
\hline & & & Marketable & Natural Culls & Bruised & Cuts \\
\hline $11 / 7 / 00$ & Van & RDA single impacts & $86.3 \mathrm{a}^{[\mathrm{a}]}$ & 6.0 & $5.3 \mathrm{a}$ & 2.3 \\
\hline $11 / 7 / 00$ & Van & Inertia shaker & $79.0 \mathrm{~b}$ & 6.3 & $10.7 \mathrm{~b}$ & 4.0 \\
\hline $12 / 7 / 00$ & Lapin & RDA single impacts & $92.3 \mathrm{a}^{[\mathrm{b}]}$ & 5.3 & $2.0 \mathrm{ab}$ & $0.3 b$ \\
\hline $12 / 7 / 00$ & Lapin & RDA multiple impacts & $85.0 \mathrm{~b}$ & 7.7 & $3.7 \mathrm{a}$ & $3.7 \mathrm{a}$ \\
\hline $12 / 7 / 00$ & Lapin & Hand harvested & $92.3 \mathrm{a}$ & 6.7 & $1.0 \mathrm{~b}$ & $0.0 \mathrm{~b}$ \\
\hline $12 / 7 / 00$ & Lapin & $1 \mathrm{~m}$ drop onto catching conveyor & $89.0 \mathrm{~b}^{[\mathrm{c}]}$ & 6.3 & $4.7 \mathrm{a}$ & 0.0 \\
\hline $12 / 7 / 00$ & Lapin & $2 \mathrm{~m}$ drop onto catching conveyor & $87.7 \mathrm{~b}$ & 8.0 & $4.3 \mathrm{a}$ & 0.0 \\
\hline $12 / 7 / 00$ & Lapin & Control & $94.3 \mathrm{a}$ & 5.3 & $0.3 b$ & 0.0 \\
\hline
\end{tabular}

[a] Comparisons between Van RDA single impacts and inertia shaker, mean separation within columns by Duncan's multiple range test, $\mathrm{P}=0.05$, $\mathrm{df}=4$.

[b] Comparison between Lapin RDA single impacts, RDA multiple impacts, and hand harvested, mean separation within columns by Duncan's Multiple range test, $\mathrm{P}=0.05, \mathrm{df}=6$.

[c] Comparison between Lapin $1 \mathrm{~m}$ drop, $2 \mathrm{~m}$ drop, and control, mean separation within columns by Duncan's multiple range test, $\mathrm{P}=0.05$, df = 6. 


\section{REFERENCES}

Bukovac, M. J., F. Zucconi, V. A. Wittenback, J. A. Flore, and H. Inoue. 1971. Effects of 2-chloroethyl phosphonic acid on development and abscission of maturing sweet cherry (Prunus avium L.). J. Amer. Soc. Hort. Sci. 96(6): 777-781.

Gaston, H. P., J. H. Levin, and S. Hedden. 1959. Experiments in harvesting cherries mechanically. Quarterly Bulletin of the Michigan Agricultural Experiment Station 41(4): 805-811. East Lansing, Mich.

Halderson J. L. 1966. Fundamental factors in mechanical cherry harvesting. Trans. ASAE 9(5): 681-684.

Hansen, M. 1999a. Prepare now for future labor shortages. Good Fruit Grower 50(3): 41-42.

1999b. No let-up expected in Border Patrol. Good Fruit Grower 50(5): 39.

1999c. Harris still working on mechanical harvesting. Good Fruit Grower 50(5): 51.

Harris, R. 2000. Personal communication with Bob Harris, fruit grower in Moxee, Wash.
Holt, J. S. 1999. Implications of reduced availability of seasonal agricultural workers on the labor intensive sector of U.S. agriculture. ASAE Paper No. 99-1095. St. Joseph, Mich.: ASAE.

Markwardt, E. D., R. W. Guest, J. C. Cain, and R. L. LaBelle. 1964. Mechanical cherry harvesting. Trans. ASAE 7(1): 70-74.

Norton, R. A., C. C. Claypool, S. Leonard, P. Adrain, R. Fridley, and F. Charles. 1962. Mechanical harvest of sweet cherries. Calif. Agr. 16(5): 8-10.

Peterson, D. L., B. S. Bennedsen, W. C. Anger, and S. C. Wolford. 1999. A systems approach to robotic bulk harvesting of apples. Trans. ASAE 42(4): 871-876.

Sarig, Y., J. F. Thompson, and G. K. Brown. 1999. The status of fruit and vegetable harvest mechanization in the U.S. ASAE Paper No. 99-1098. St. Joseph, Mich.: ASAE.

Warner, G. 1997. Workforce shrinks as Border Patrol moves in. Good Fruit Grower 48(10): 16. 
